\title{
Volatile Fatty Acids in Liquid Swine Manure Can Kill Microsclerotia of Verticillium dahliae
}

\author{
Mario Tenuta, Kenneth L. Conn, and George Lazarovits
}

First author: Department of Plant Sciences, University of Western Ontario, London, ON, Canada; and second and third authors: Southern

Crop Protection and Food Research Centre, Agriculture and Agri-Food Canada, 1391 Sandford Street, London, ON, Canada N5V 4T3.

Current address of M. Tenuta: Department of Nematology, University of California, One Shields Ave., Davis 95616.

Accepted for publication 29 January 2002.

\begin{abstract}
Tenuta, M., Conn, K. L., and Lazarovits, G. 2002. Volatile fatty acids in liquid swine manure can kill microsclerotia of Verticillium dahliae. Phytopathology 92:548-552.

Liquid swine manure added to acidic soils killed microsclerotia of the wilt fungus Verticillium dahliae. We investigated whether volatile fatty acids (VFAs) in the manure were responsible for this toxicity. The survival of microsclerotia was determined after exposure to various dilutions of manure or its VFA components. Acetic, propionic, and isobutyric acids constituted the major VFAs in the manure, while $n$-butyric, $n$-valeric, isovaleric, and $n$-caproic acids were present in lesser amounts. Formic acid was not detected. The individual VFAs were more toxic to microsclerotia as the solution $\mathrm{pH}$ was decreased, indicating that the protonated forms of

the VFAs were toxic (e.g., acetic acid and not acetate). The effective concentration reducing germination of microsclerotia by $95 \%\left(\mathrm{EC}_{95}\right)$ for formic and $n$-caproic acids was approximately $4 \mathrm{mM}$, the most toxic of the acids tested; for $n$-valeric, the $\mathrm{EC}_{95}$ was $9.2 \mathrm{mM}$, isovaleric was $16.1 \mathrm{mM}$ acids, and acetic, propionic, $n$-butyric, and isobutyric acids were approximately $30 \mathrm{mM}$. The toxicity of acetic acid, and likely all the others, was directly related to the duration of exposure. Inhibition of microsclerotia germination followed identical trends in solutions of the manure or in a mixture of VFAs with equivalent concentrations of the individual acids found in the manure. Similarly, germination declined to the same extent in the atmosphere above the manure or the VFA mixture, confirming the toxicity of VFAs to microsclerotia. Thus, under acid conditions, VFAs in liquid swine manure can kill microsclerotia of $V$. dahliae.
\end{abstract}

Addition of liquid swine manure (LSM) to a potato field (site B) soil reduced the incidences of Verticillium wilt caused by Verticillium dahliae Kleb., common scab caused by Streptomyces scabies (Thaxter) Lambert \& Loria, and populations of plantparasitic nematodes for up to 3 years after a single application (4). This LSM however, had little or no effect on the above diseases at a second field location (4) or on the survival of microsclerotia in soils from various sites when tested in soil microcosm experiments (5). Yet, microsclerotia of $V$. dahliae were killed after 1 day in site B soil amended with LSM (5). The major factor in determining whether this or other LSM were toxic to microsclerotia was soil $\mathrm{pH}$ (5). This led us to suspect that volatile fatty acids (VFAs) in the manure may be responsible for the toxicity to microsclerotia of $V$. dahliae. The chemical configuration in which VFAs assume in soil (nonionized/ionized forms) is dependent upon soil $\mathrm{pH}$ and this may be a major determinant of efficacy of LSM to control disease.

Short-chain VFAs such as acetic, propionic, butyric, valeric, and caproic acids are metabolic products of bacterial anaerobic fermentation and have been detected in liquid manures such as LSM when stored anaerobically $(6,14,25)$. These compounds kill human and animal pathogens $(13,17,20)$, food spoilage organisms $(7,11)$, and crop plants $(10,22)$. High concentrations of acetic, propionic, isobutyric, butyric, and isovaleric acids were responsible for phytotoxicity of immature compost (8). Similarly, the inhibition of growth of Brassica rapa L. by immature compost was related primarily to toxicity of propionic and $n$-butyric acids (3). The phytotoxicity often seen following incorporation of green

Corresponding author: G. Lazarovits; E-mail address: lazarovitsg@em.agr.ca

Publication no. P-2002-0320-02R

For the Department of Agriculture and Agri-Food, Government of Canada (C) Minister of Public Works and Government Services Canada 2002 manures was related to production of acetic acid produced during microbial degradation $(21,22)$. VFAs are frequently added to silage and fruit to prevent rot, and acetic acid and propionic acids are used as food preservatives $(9,12,19,24,27)$. The effect of VFAs on survival of soilborne plant pathogens is unknown, although they might be detrimental to them because acetic acid in freshly composted municipal wastes suppressed infection of citrus seedlings by, and colony growth of, Phytophthora nicotianae Breda de Haan (31).

It is the nonionized forms of VFAs that are toxic $(12,13,30)$. The proportion of ionized (e.g., acetate) to nonionized (e.g., acetic acid) form of a VFA is dependent upon the $\mathrm{pH}$ of the solution. The concentration of the nonionized form of an individual VFA in solution is estimated using the Henderson-Hasselbalch equation (15) as follows:

$$
\mathrm{mM} \text { nonionized VFA }=\frac{\mathrm{mM} \text { (nonionized plus ionized VFA })}{\left(\frac{\left.10^{(-\mathrm{p} \mathrm{K}} \mathrm{a}\right)}{10^{(-\mathrm{pH})}}+1\right)}
$$

where $\mathrm{mM}$ (nonionized plus ionized VFA) = concentration of a VFA in solution (millimolar), $\mathrm{pK}_{\mathrm{a}}\left(24^{\circ} \mathrm{C}\right)=$ equilibrium constant.

Reports of toxicity of VFAs to crop plants $(3,9,21,22)$, food spoilage organisms $(7,11)$, and a plant pathogen (31) did not include calculations of the concentration of nonionized forms of VFAs, although required for the effective use of VFAs in agricultural systems.

The objective of this study was to determine if short-chain fatty acids are present in LSM and if they can kill microsclerotia of $V$. dahliae. For this, we used LSM shown in previous studies to kill microsclerotia in acidic soils $(4,5)$. Preliminary results of this study have been presented (29). 


\section{MATERIALS AND METHODS}

Manure. LSM was collected in May 1996 from a lagoon at a swine operation near Alliston, ON. Some of this manure was used in field (4) and soil microcosm (5) studies. The rest was stored frozen until needed. The manure had a $\mathrm{pH}$ of 7.7, 5.7\% dry mass, $2.3 \%$ total $\mathrm{C}, 0.8 \%$ total $\mathrm{N}, 0.1 \% \mathrm{P}_{2} \mathrm{O}_{5}, 0.4 \%$ potassium, and $4,660 \mathrm{mg}$ of $\mathrm{NH}_{4}^{+}-\mathrm{N}$ per $\mathrm{kg}$ fresh mass.

Analysis of VFAs in LSM. Particulates in LSM were removed by centrifugation $(10 \mathrm{~min}$ at $10,600 \times g)$. The concentrations of individual VFAs in LSM were determined using chemical suppression ion exclusion chromatography and conductivity detection (Model 100; Dionex Corp., Sunnyvale, CA). The chromatograph was equipped with an IonPac ICE-AS6 analytical column and AMMS ICE II chemical suppressor (Dionex Corp.). LSM contained in vials were introduced $(40 \mu \mathrm{l})$ to the ion chromatograph by an autosampler equipped with a refrigerated chamber housing the vials (Waters 717plus; Waters Associates, Milford, MA). Samples were diluted 1,000 times for the determination of total acetic acid, 10 times for isovaleric and caproic acids, and 100 times for all other VFAs. The concentration of calibrants ranged from 0 to $1.5 \mathrm{mM}$ for individual VFAs. The concentration of nonionized acid was estimated with the Henderson-Hasselbalch equation.

$\boldsymbol{V}$. dahliae microsclerotia bioassay. A single-spore isolate of $V$. dahliae obtained from an eggplant (Solanum melongena L. cv. Imperial Black Beauty) grown in $V$. dahliae-infested soil was reared on semisolid Czapek-Dox medium for 3 weeks in the dark at $24^{\circ} \mathrm{C}$. The culture was poured through mesh screens to obtain microsclerotia between 76 and $106 \mu \mathrm{m}$ in diameter (16). The microsclerotia were stored in the dark at $24^{\circ} \mathrm{C}$ prior to use. Microsclerotia $(15 \mathrm{mg})$ were then added to crushed silica sand $(1 \mathrm{~g})$ par- ticles sorted to between 75 and $106 \mu \mathrm{m}$. Approximately $25 \mathrm{mg}$ of this mixture was added to a mesh bag (approximately $15 \times 20 \mathrm{~mm}$ ) prepared from polyester screening (Saatilene High Tech Fabric; 48- $\mu$ m pore size; SAATI S.p.A., Como, Italy). The bag was sealed and used in solution bioassay experiments to follow. At various times, microsclerotia were removed from the bioassays and distributed onto agar plates containing soil-pectate-tergitol agar (16) using an Andersen cascade impactor with 0.81- and 1.18-mmpore-diameter sieves (Andersen Instruments Inc., Smyrna, GA). The microsclerotia were incubated for 2 weeks in the dark at $24^{\circ} \mathrm{C}$ and examined microscopically. A $0.25-\mathrm{cm}^{2}$ sectioned grid was placed on the base of a dissecting microscope. A plate was placed on the grid and scanned systematically at $\times 20$ magnification until 50 microsclerotia had been examined and scored for the formation of colonies. The viability of microsclerotia was determined as the percentage of the 50 examined that germinated to form colonies. Microsclerotia positioned too close to one another to differentiate, which had led to the formation of a colony, were excluded from examination. Also excluded from examination were microsclerotia smaller than grains of sand because they were nonviable within a few weeks of being obtained from culture (16).

Toxicity to microsclerotia of individual VFAs. To examine the toxicity of ionized and nonionized forms of VFAs present in

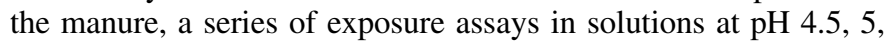
and 5.5 were carried out using the manure and individual VFAs present in the manure. This $\mathrm{pH}$ range was chosen because LSM had been demonstrated to be toxic to $V$. dahliae in soils in this $\mathrm{pH}$ range $(4,5)$. The effect on germination of microsclerotia of increasing concentrations of nonionized VFAs was examined by exposure assays in solution. Buffered solutions of citric acid-NaOH at $\mathrm{pH} 4.5,5$, and $5.5( \pm 0.03)(26)$ and of increasing concentrations of sodium acetate $(0,3.5,7,14,28$, and $56 \mathrm{mM}$; Sigma Chemical,

TABLE 1. Characteristics and concentrations of short-chain volatile fatty acids (VFAs) in the liquid swine manure used in this study

\begin{tabular}{|c|c|c|c|c|c|c|}
\hline VFA & Formula & Molecular weight & Solubility $(\mathrm{mM})^{\mathrm{a}}$ & Henry's constant $\mathrm{M} /\left(\mathrm{atm} \times 10^{3}\right)^{\mathrm{a}}$ & $\mathrm{pK}_{\mathrm{a}}^{\mathrm{b}}$ & Concentration $(\mathrm{mM})^{\mathrm{c}}$ \\
\hline Formic & $\mathrm{HCOOH}$ & 46.0 & $>5,000$ & 5.5 & 3.75 & 0.0 \\
\hline Acetic & $\mathrm{CH}_{3} \mathrm{COOH}$ & 60.1 & $>5,000$ & 5.5 & 4.76 & 270.0 \\
\hline Propionic & $\mathrm{CH}_{3} \mathrm{CH}_{2} \mathrm{COOH}$ & 74.1 & 5,000 & 5.7 & 4.86 & 59.0 \\
\hline$n$-Butyric & $\mathrm{CH}_{3}\left(\mathrm{CH}_{2}\right)_{2} \mathrm{COOH}$ & 88.1 & 1,100 & 4.7 & 4.83 & 16.3 \\
\hline Isobutyric & $\left(\mathrm{CH}_{3}\right)_{2} \mathrm{CHCOOH}$ & 88.1 & 1,900 & 1.1 & 4.83 & 38.0 \\
\hline$n$-Valeric & $\mathrm{CH}_{3}\left(\mathrm{CH}_{2}\right)_{3} \mathrm{COOH}$ & 102.1 & 300 & 2.2 & 4.80 & 17.6 \\
\hline Isovaleric & $\left(\mathrm{CH}_{3}\right)_{2} \mathrm{CHCH}_{2} \mathrm{COOH}$ & 102.1 & 400 & 1.2 & 4.80 & 3.6 \\
\hline$n$-Caproic & $\mathrm{CH}_{3}\left(\mathrm{CH}_{2}\right)_{4} \mathrm{COOH}$ & 116.2 & 100 & 1.4 & 5.05 & 9.0 \\
\hline Total & & & & & & 413.5 \\
\hline
\end{tabular}

a Values obtained from literature citation 18.

${ }^{\mathrm{b}} \mathrm{pH}$-dependent equilibrium constant obtained from literature citation 26.

${ }^{c}$ Concentration of nonionized plus ionized forms of each VFA.

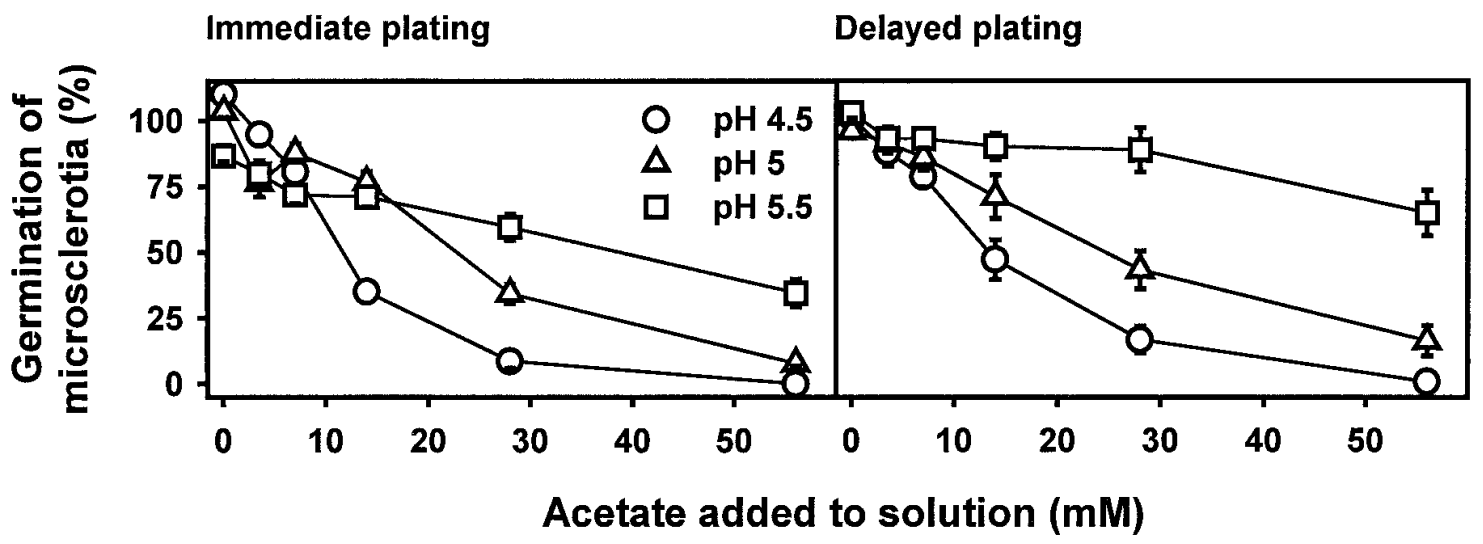

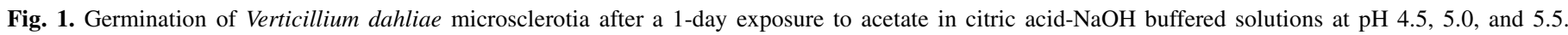

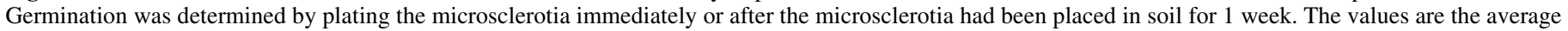
of two experiments with three replicates for each treatment $(n=6 \pm \mathrm{SE})$. 
St. Louis) were prepared. The concentration of nonionized acid was estimated with the Henderson-Hasselbalch equation. Each solution was filter sterilized $(<0.22-\mu \mathrm{m}$ pore size $)$ and added $(15 \mathrm{ml})$ to autoclaved glass test tubes of $15.5-\mathrm{ml}$ capacity. There were three replicate tubes per treatment. Two mesh bags containing microsclerotia were submerged in the solution in each tube, and the tubes were closed and incubated in the dark at $24^{\circ} \mathrm{C}$ for 1 day. The mesh bags were retrieved, rinsed with sterile distilled water, and dried at room temperature for $3 \mathrm{~h}$. The viability of microsclerotia from one of the dried bags in each test tube was immediately determined and for the other bag after placement in a sandy loam soil for 1 week. The $\mathrm{pH}$ and concentration of VFAs in solutions were determined after the retrieval of mesh bags from tubes. This experiment was also performed using formic, propionic, $n$-butyric, isobutyric, $n$-valeric, isovaleric, and $n$-caproic acids (Sigma Chemical) individually added to the buffered solutions. Each experiment using an individual VFA was performed twice.

Effect of exposure duration on the toxicity of acetic acid. Citric acid- $\mathrm{NaOH}$ buffered solutions at $\mathrm{pH} 5$ and containing sodium acetate were prepared forming solutions with $0,5,10$, and $20 \mathrm{mM}$ acetic acid. The solutions were filter sterilized and added $(15 \mathrm{ml})$ to three sterile test tubes per treatment. One mesh bag containing microsclerotia was submerged in the solution in each tube and the tubes were closed and incubated for 1,2, or 4 days in the dark at $24^{\circ} \mathrm{C}$. The mesh bags were retrieved from the

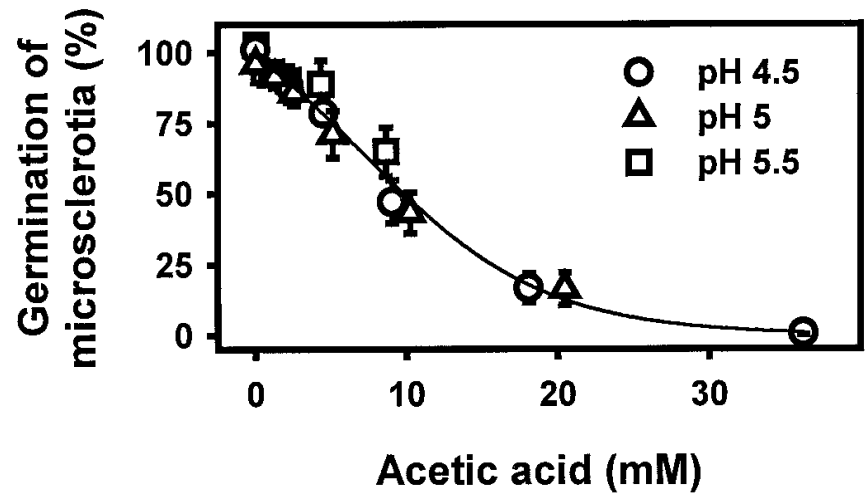

Fig. 2. Germination of Verticillium dahliae microsclerotia as a function of the concentration of acetic acid (millimolar) in citric acid-NaOH buffered solutions at $\mathrm{pH}$ 4.5, 5.0, and 5.5. Germination was determined after the microsclerotia had been placed in soil for 1 week. The concentration of acetic acid was determined using the Henderson-Hasselbalch equation, the concentration of acetate added to the solution, and the $\mathrm{pH}$ of the solution. The values are the average of two experiments with three replicates for each treatment $(n=6 \pm \mathrm{SE})$.

TABLE 2. The concentration of individual volatile fatty acids (VFAs) required to reduce the germination of Verticillium dahliae microsclerotia by $95 \%\left(\mathrm{EC}_{95}\right)^{\mathrm{a}}$

\begin{tabular}{lccc}
\hline & & \multicolumn{2}{c}{ Confidence interval } \\
\cline { 3 - 4 } VFA & $\mathrm{EC}_{95}(\mathrm{mM})$ & $95 \%$ & $99 \%$ \\
\hline Formic & 3.6 & \pm 0.7 & \pm 1.0 \\
Acetic & 26.2 & \pm 2.2 & \pm 2.8 \\
Propionic & 27.0 & \pm 7.0 & \pm 9.3 \\
$n$-Butyric & 29.0 & \pm 4.1 & \pm 5.3 \\
Isobutyric & 32.8 & \pm 6.5 & \pm 8.6 \\
$n$-Valeric & 9.2 & \pm 1.4 & \pm 1.8 \\
Isovaleric & 16.1 & \pm 1.5 & \pm 1.9 \\
$n$-Caproic & 4.1 & \pm 0.5 & \pm 0.7 \\
\hline
\end{tabular}

a The $\mathrm{EC}_{95}$ was estimated by fitting to each replicate data set the percent germination of microsclerotia as a function of the concentration of nonionized VFA using a sigmoidal model. The values are the average of two experiments with three replicates for each treatment $(n=6)$. solutions, rinsed with sterile distilled water, dried at room temperature for $3 \mathrm{~h}$, and placed into soil for 1 week prior to determining microsclerotia germination. This experiment was performed twice.

Toxicity of LSM and a mixture of VFAs present in the manure. The toxicity to microsclerotia of a mixture of VFAs equivalent to LSM was compared with that of the manure. Citric acid- $\mathrm{NaOH}$ buffered solutions at $\mathrm{pH} 4.5,5$, and 5.5 containing 0 , $1.5,2.5,5,10$, and $15 \%$ (vol/vol) LSM or the VFA mixture were prepared and filter sterilized. The solutions were added $(15 \mathrm{ml})$ to three sterile test tubes per treatment, and one mesh bag containing microsclerotia was submerged in the solution in each tube. The tubes were closed and incubated for 1 day in the dark at $24^{\circ} \mathrm{C}$. The mesh bags were retrieved from the solutions, rinsed with sterile distilled water, dried at room temperature for $3 \mathrm{~h}$, and placed into soil for 1 week prior to determining microsclerotia germination. This experiment was performed twice.

Toxicity of volatiles from LSM and the VFA mixture. The toxicity to microsclerotia of volatiles from LSM and the mixture of VFAs was compared. Citric acid-NaOH buffered solutions at pH 5 containing $0,5,10,15,20,30$, and $40 \%$ ( vol/vol) LSM or the VFA mixture were prepared and filter sterilized. The solutions were added $(50 \mathrm{ml})$ to three sterile wide-mouth mason jars $(250 \mathrm{ml})$ per treatment, and a mesh bag containing microsclerotia was suspended in the headspace of each jar. The jars were closed and incubated for 1 day in the dark at $24^{\circ} \mathrm{C}$, and microsclerotia germination was determined after placement of the bags in soil for 1 week. This experiment was performed twice.

Statistical analyses. The toxicity of nonionized forms of individual VFAs was determined as the concentration that reduced the germination of $V$. dahliae microsclerotia to $5 \%\left(\mathrm{EC}_{95}\right)$. The data for each individual VFA did not fit the probit distribution as determined by chi-square test at $P=0.05$ (Probit Program, U.S. Environmental Protection Agency, Cincinnati; version 1.5). Thus, the data for each replicate were fit to a sigmoidal model $(y=$ $a /\left(1+10^{\{-[(x-x 0) / b]\}}\right)$ using the computer software SigmaStat 2000 (SPSS Inc., Chicago). The model was appropriate with the goodness of fit to every data set at $r^{2}>0.92$ and $P<0.0001$. The parameter coefficients in each fitted model contributed to predicting the germination of microsclerotia as examined by the $t$ statistic (the ratio of the coefficient of each parameter to the standard error of the model). The population of data was normally distributed about each regression line as examined by the KolmogorovSmirnov test $(P>0.05)$. The results are presented as the average $\mathrm{EC}_{95}( \pm 95 \%$ confidence interval) of six replicates.

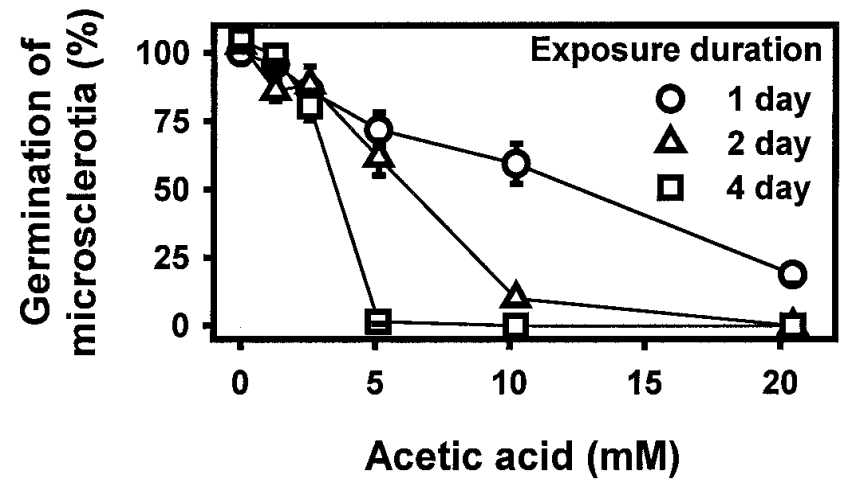

Fig. 3. Germination of Verticillium dahliae microsclerotia as a function of the duration of exposure to acetic acid (millimolar) in citric acid- $\mathrm{NaOH}$ buffered solutions at $\mathrm{pH}$ 5.0. Microsclerotia were placed in solutions of sodium acetate for 1,2 , and 4 days. The concentration of acetic acid was determined using the Henderson-Hasselbalch equation. Germination was determined after the microsclerotia had been placed in soil for 1 week. The values are the average of two experiments with three replicates for each treatment $(n=6 \pm \mathrm{SE})$. 


\section{RESULTS}

VFAs in LSM. Acetic acid was the predominant VFA in the LSM constituting $65 \%$ of the total VFAs in the manure (Table 1). Propionic and isobutyric acids were present in lesser amounts at 14 and $9 \%$ of the total VFAs present, respectively (Table 1). $n$ Butyric, $n$-valeric, isovaleric, and $n$-caproic acids were present in very low levels with each being less than $4 \%$ of the total VFAs in the LSM (Table 1). Formic acid was not detected in the manure. From other reports, the solubility and volatility (Henry's constant) of VFAs present in the manure is expected to decrease as the molecular weight and length of lipophilic side chains increase (Table 1).

Effect of delayed plating of microsclerotia. Germination of microsclerotia following exposure to increasing concentrations of acetic acid (Fig. 1) and of other VFAs (data not shown) were slightly higher if microsclerotia were placed in soil for 1 week than if they were plated immediately after removal from the solutions. Thus, for all subsequent experiments, microsclerotia were placed in soil prior to determination of germination.

Toxicity of individual VFAs. Germination of microsclerotia declined with increasing concentrations of individual VFAs and acidity of solution. The response in germination to concentrations of individual VFAs and acidity is typified by acetic acid. At the lowest $\mathrm{pH}$ examined, germination declined rapidly with an increase in concentration of acetic acid such that all microsclerotia were dead at the highest concentration examined $(55 \mathrm{mM})$ (Fig. 1). Germination of microsclerotia declined as a function of the concentration of nonionized VFA in solution (Fig. 2). The smallest (formic) and largest ( $n$-caproic) of the VFAs examined were most
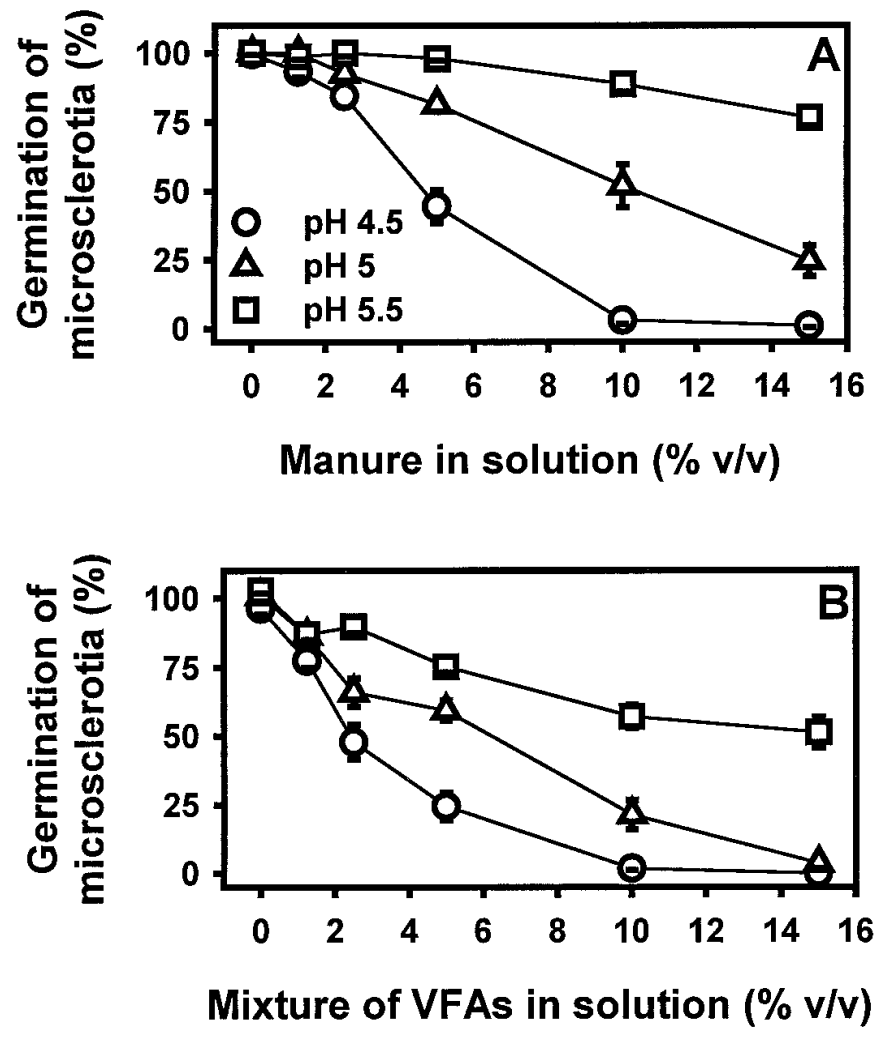

Fig. 4. Germination of Verticillium dahliae microsclerotia as a function of the concentration (\%, vol/vol) in $\mathbf{A}$, liquid swine manure, and $\mathbf{B}$, a mixture of volatile fatty acids (VFAs) in citric acid- $\mathrm{NaOH}$ buffered solutions at $\mathrm{pH} 4.5$, 5.0, and 5.5. The mixture of VFAs was prepared with individual VFA components at the same concentration as found in the manure (Table 1). Microsclerotia were placed in the solutions for 1 day and their germination was determined after 1 week in soil. The values are the average of two experiments with three replicates for each treatment $(n=6 \pm \mathrm{SE})$. toxic to microsclerotia (Table 2). Generally, the toxicity of VFAs decreased slightly from the $\mathrm{C}_{2}$ acetic to the $\mathrm{C}_{4}$ isobutyric acid (Table 2). Toxicity increased with an increase in size to the $\mathrm{C}_{5} n$ valeric and the $\mathrm{C}_{6} n$-caproic acids (Table 2 ). The toxicity of the two isoforms of butyric and valeric acids were less than the $n$ forms (Table 2). The lethal concentration of acetic acid decreased with the duration of exposure of microsclerotia to acetic acid in solution (Fig. 3).

Toxicity of LSM and the VFA mixture. Germination of microsclerotia declined with increasing concentration and acidity of LSM (Fig. 4A) or an equivalent mixture of VFAs as in the manure (Fig. 4B). Germination was completely prevented at concentrations of 10 and $15 \%(\mathrm{vol} / \mathrm{vol})$ of the LSM and the mixture of VFAs at $\mathrm{pH} 4.5$ (Fig. 4). The VFA mixture was slightly more toxic to microsclerotia than LSM (Fig. 4).

The germination of microsclerotia declined to a similar extent when placed in the atmosphere above solutions of increasing concentrations of LSM and the VFA mixture (Fig. 5). The $40 \%$ ( vol/vol) solutions did not completely kill the microsclerotia but reduced the germination to only $20 \%$ (Fig. 5).

\section{DISCUSSION}

Previous studies conducted by our laboratory reported that addition of LSM to soil can kill $V$. dahliae microsclerotia $(4,5)$. This study demonstrates that a mixture of VFAs comparable to that found in the LSM had similar toxicity to microsclerotia. Thus, VFAs in LSM account for the toxicity of LSM to microsclerotia in acid soils found in those previous microcosm experiments. Acidity promotes the protonation and generation of nonionized forms of short-chain VFAs in LSM killing microsclerotia. This explains why the effectiveness of the manure was eliminated if the $\mathrm{pH}$ of the soil was increased from 5 to 6.5 (5).

Acetic acid was the predominant VFA (64\% of total) in the LSM with propionic acid present also in substantial concentration (14\%). The other VFAs individually comprised no more than $9 \%$ of the total concentration and formic acid was undetected. Similar compositions of VFAs for LSM and liquid manures of cattle and dairy cows have been reported $(6,25)$. VFAs are produced during anaerobic decomposition of liquid manures (14) and of organic matter during composting $(3,9)$. Based on the results shown here, nonionized forms of VFAs have similar toxicity to a plant pathogen as to human and animal intestinal pathogens reported by others $(13,17,20)$

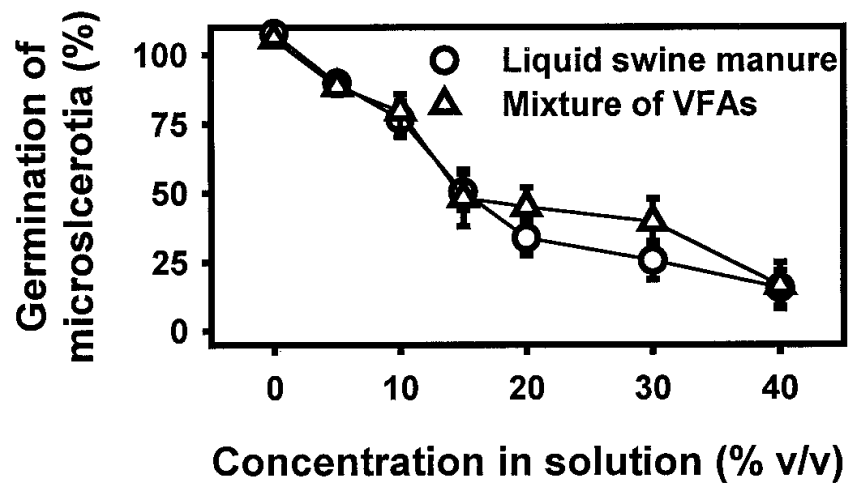

Fig. 5. Germination of Verticillium dahliae microsclerotia retrieved from the atmosphere above citric acid- $\mathrm{NaOH}$ buffered solutions ( $\mathrm{pH}$ 5) containing liquid swine manure (LSM) and a mixture of volatile fatty acids (VFAs). The mixture of VFAs was prepared with concentrations of individual VFA components the same as the LSM (Table 1). Microsclerotia were placed in the atmosphere above the solutions for 1 day. Their germination was determined after 1 week in soil. The values are the average of two experiments with three replicates for each treatment $(n=6 \pm \mathrm{SE})$. 
The mechanism by which VFAs are toxic to $V$. dahliae is unknown. However, it was the nonionized forms of VFAs that were toxic to $V$. dahliae microsclerotia in this study and to nonplant pathogenic organisms in other studies $(12,13,30)$. The nonionized form of ammonium, ammonia, is capable of readily penetrating cell membranes and is the form generally toxic to organisms $(2,23)$. Similarly, nonionized forms of VFAs may easily penetrate cell membranes.

The ability of compounds to penetrate cell membranes is reduced by their size and the solubility in water (1). A tendency for slightly reduced toxicity with increasing size of VFAs from the $\mathrm{C}_{2}$ acetic acid to the $\mathrm{C}_{4}$ butyric acids and increased toxicity for the larger, lipophilic $\mathrm{C}_{5}$ valeric and $\mathrm{C}_{6} n$-caproic acids suggests that it is the ability to penetrate cells that determines toxicity. This was also noted by Freese et al. (12) with the bacterium Bacillus subtilis (Ehrenberg) Cohn. Presumably, the lipophilic long chain of VFAs greater than $\mathrm{C}_{4}$ promotes the penetration cell membranes. Such molecules somehow inhibit the uptake of substrates such as amino acids, organic acids, and phosphate by inhibiting oxidative phosphorylation of active transport systems in cell membranes (12). However, the inhibition is reversible because when cells were resuspended in medium lacking VFAs, growth resumed immediately (12). We found exposure of microsclerotia to sublethal concentrations of LSM or VFAs followed by immediate plating resulted in a lower germination of microsclerotia than if the microsclerotia were incubated in soil for a further 7 days before plating. A moderate reversal in inhibition of germination of microsclerotia has been observed for sublethal concentrations of LSM in acidic soil (5), and to ammonia in soil and solutions (28). Thus, placement of the microsclerotia in soil for a while allows them to recover from the presumed stress of sublethal concentrations of some toxicants prior to placement onto germination medium, resulting in a truer indication of the percentage of microsclerotia killed by an amendment such as LSM.

In addition to increasing acidity of solution, increasing duration of exposure decreased the lethal concentration of acetic acid necessary to kill $V$. dahliae microsclerotia. Thus, lower concentrations of LSM will be required to kill $V$. dahliae if the manure is acidified and in contact with microsclerotia for longer periods of time. This also implies that the rate of degradation of VFAs in soil will be a factor determining the effectiveness of LSM.

In conclusion, we have demonstrated that LSM can contain short-chain VFAs of $\mathrm{C}_{2}$ (acetic acid) to $\mathrm{C}_{6}$ (n-caproic acid) that can kill microsclerotia of $V$. dahliae. It is the protonation of VFAs in acidic solution that generates nonionized forms toxic to the pathogen. This explains the observation that LSM kills microsclerotia in acid soil $(4,5)$. We are currently investigating the toxicity of VFAs to other soilborne plant pathogens and the effectiveness of LSM addition to acidic soil or as an acidified foliar solution to control plant pathogens.

\section{ACKNOWLEDGMENTS}

This study was funded by grants from Ontario Pork, Can-Adapt Program, and the Matching Investment Initiative of Agriculture and AgriFood Canada. We thank D. Jensen and C. Kocela for technical assistance.

\section{LITERATURE CITED}

1. Alberts, B., Bray, D., Lewis, J., Raff, M., Roberts, K., and Watson, J. D. 1994. Molecular Biology of the Cell. 3rd ed. Garland Publishing, New York.

2. Buurman, E. T., Teixeira de Mattos, M. J., and Neijssel, O. M. 1989. Nitrogen-limited behaviour of micro-organisms growing in the presence of large concentrations of ammonium ions. FEMS Microbiol. Lett. 58:229-232.

3. Chanyasak, V., Katayama, A., Hirai, M. F., Mori, S., and Kubota, H. 1983. Effects of compost maturity on growth of Komatsuna (Brassica rapa var. pervidis) in Neubauer's pot. II. Growth inhibitory factors and assessment of degree of maturity by org.-C/org.-N ratio of water extract. Soil Sci. Plant Nutr. 29:251-259.

4. Conn, K. L., and Lazarovits, G. 1999. Impact of animal manures on Verticillium wilt, potato scab, and soil microbial populations. Can. J. Plant Pathol. 21:81-92.

5. Conn, K. L., and Lazarovits, G. 2000. Soil factors influencing the efficacy of liquid swine manure added to soil to kill Verticillium dahliae. Can. J. Plant Pathol. 22:400-406.

6. Cooper, P., and Cornforth, I. S. 1978. Volatile fatty acids in stored animal slurry. J. Sci. Food Agric. 29:19-27.

7. Corsetti, A., Gobbetti, M., Rossi, J., and Daminani, P. 1998. Antimould activity of sourdough lactic acid bacteria: Identification of a mixture of organic acids produced by Lactobacillus sanfrancisco CB1. Appl. Microbiol. Biotechnol. 50:253-256.

8. DeVleeschauwer, D., Verdonck, O., and Van Assche, P. 1981. Phytotoxicity of refuse compost. Biocycle 22:44-46.

9. Doores, S. 1993. Organic acids. Pages 95-136 in: Antimicrobials in Food. P. M. Davidson and A. L. Banen, eds. Marcel Dekker, New York.

10. Edney, N. A., and Rizvi, M. 1996. Phytotoxicity of fatty acids present in dairy and hog manure. J. Environ. Sci. Health Part B Pestic. Food Contam. Agric. Wastes 31:269-281.

11. Esgalhado, M. E., Roseiro, J. C., and Amaral-Collaco, M. T. 1996. Kinetics of acid toxicity in cultures of Xanthomonas campestris. Food Microbiol. 13:441-446.

12. Freese, E., Sheu, C. W., and Galliers, E. 1973. Function of lipophilic acids as antimicrobial food additives. Nature 241:321-325

13. Goepfert, J. M., and Hicks, R. 1969. Effect of volatile fatty acids on Salmonella typhimurium. J. Bacteriol. 97:956-958.

14. Guenzi, W. D., and Beard, W. E. 1981. Volatile fatty acids in a redoxcontrolled cattle manure slurry. J. Environ. Qual. 10:479-482.

15. Hasselbalch, K. A. 1916. Die berechnung der wasserstoffzahl der Blutes aus der frien gebundenen kahlensaure desselben, und die Sauerstoffbindung des Blutes als funktion der wasserstoffzahl. Biochem. Z. 78:112-144.

16. Hawke, M. A., and Lazarovits, G. L. 1994. Production and manipulation of individual microsclerotia of Verticillium dahliae for use in studies of survival. Phytopathology 84:883-890.

17. Kenealy, W. R., Cao, Y., and Weiner, P. J. 1995. Production of caproic acid by cocultures of ruminal cellulolytic bacteria and Clostridium kluyveri grown on cellulose and ethanol. Appl. Microbiol. Biotechnol. 44:507-513.

18. Khan, I., Brimblecombe, P., and Clegg, S. L. 1995. Solubilities of pyruvic acid and the lower (C1-C6) carboxylic acids. Experimental determination of equilibrium vapour pressures above pure aqueous and salt solutions. J. Atmos. Chem. 22:285-302.

19. Khonga, E. B., and Sutton, J. C. 1991. Effects of acetic acid, propionic acid and urea on inoculum production by Gibberella zeae in maize and wheat residues. Mycol. Res. 95:409-412.

20. Kunte, D. P., Yeole, T. Y., Chiplonkar, S. A., and Ranade, D. R. 1998. Inactivation of Salmonella typhi by high levels of volatile fatty acids during anaerobic digestion. J. Appl. Microbiol. 84:138-142.

21. Lynch, J. M. 1977. Phytotoxicity of acetic acid produced in the anaerobic decomposition of wheat straw. J. Appl. Bacteriol. 42:81-87.

22. Lynch, J. M. 1978. Production and phytotoxicity of acetic acid in anaerobic soils containing plant residues. Soil Biol. Biochem. 10:131-135.

23. Macmillan, A. 1956. The entry of ammonia into fungal cells. J. Exp. Bot. 7:113-126

24. Ohyama, Y., Hara, S., and Masaki, S. 1977. The use of caproic acid to prevent aerobic deterioration of silages (Lolium nultiflorum, Dactylis) after opening, with special reference to the amounts and time of application. J. Sci. Food Agric. 28:369-374.

25. Patni, N. K., and Jui, P. Y. 1985. Volatile fatty acids in stored dairy-cattle slurry. Agric. Wastes 13:159-178.

26. Perrin, D. D., and Dempsey, B. 1974. Buffers for $\mathrm{pH}$ and Metal Ion Control. Chapman \& Hall, New York.

27. Sholberg, P. L. 1998. Fumigation of fruit with short-chain organic acids to reduce the potential of postharvest decay. Plant Dis. 82:689-693.

28. Tenuta, M. 2001. Nitrogen transformation products from nitrogenous amendments and the soil properties affecting their toxicity to Verticillium dahliae Kleb. Ph.D. diss. University of Western Ontario, London, Canada.

29. Tenuta, M., Conn, K. L., and Lazarovits, L. 2001. Volatile fatty acids in liquid swine manure kill the microsclerotia of Verticillium dahliae. (Abstr.) Can. J. Plant Pathol. 23:207.

30. Wallace, R. J., Falconer, M. L., and Bhargava, P. K. 1989. Toxicity of volatile fatty acids at rumen $\mathrm{pH}$ prevents enrichment of Escherichia coli by sorbitol in rumen contents. Curr. Microbiol. 19:277-281.

31. Widmer, T. L., Graham, J. H., and Mitchell, D. J. 1998. Composted municipal waste reduces infection of citrus seedlings by Phytophthora nicotianae. Plant Dis. 82:683-688. 